\title{
Third general meeting of PMIP3
}

\author{
Michel Crucifix', E. Zorita ${ }^{2}$ and J.-Y. Peterschmitt ${ }^{3}$
}

Namur, Belgium, 25-30 May 2014

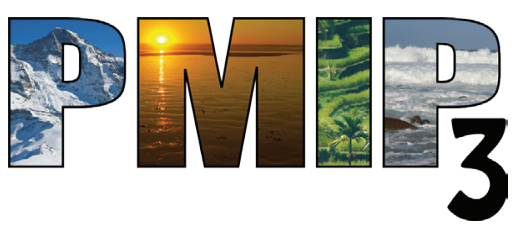

This workshop, which gathered 108 delegates, was the twelfth event of the Paleoclimate Modelling Intercomparison Project (PMIP) in a series initiated in 1995 in Collonges-la-Rouge, France. Each of the successive meetings has marked a development in the PMIP project: towards more comprehensive Earth System models, a broader range of past periods, high-standard dataset documentation, state-of-the-art approaches of model-data synthesis, and, more recently, the introduction of transient experiments (last millennium and deglaciation) and methods of data assimilation. Now in its third phase, PMIP's mission is to model and reconstruct past climates and understand the implications of this research for future climate. It has become an important contributor to our understanding of Earth's climate dynamics and sensitivity.

The workshop started with a review of database technology and the current upload status of PMIP3 experiments (https://wiki. Isce.ipsl.fr/pmip3/doku.php/pmip3:database:status). The PMIP3 database is now fully integrated within the Climate Modelling Intercomparison Project system (http:// esgf-node.ipsl.fr/) and synthesis maps are available. To complement reports from PMIP participating groups, guests from the data and modeling community were invited to deliver talks and contribute to discussions in order to provide an outsider view on PMIP's achievements and perspectives: Eelco Rohling (Australian National University), Simon Tett (University of Edinburgh), Steve Sherwood (University of New South Wales, Australia) and James Zachos (University of California Santa Cruz).

The Namur meeting made it clear that better cooperation and knowledge exchange between researchers working on proxy records and paleo modeling is essential, be it to estimate variability indices throughout the last millennium, estimate the Last Glacial Maximum temperature, or reconstruct Pliocene, Eocene, or even Devonian climates (Fig. 1). There is no magic recipe that would simultaneously provide unbiased reconstructions of past climates, reveal model deficiencies and identify anomalous observations. Effective approach will rely on an ensemble of methods, including advanced physical and biogeochemical modeling, creative visualization diagnostics, careful analysis of observations, innovative experiment design, and technical statistical inference approaches.

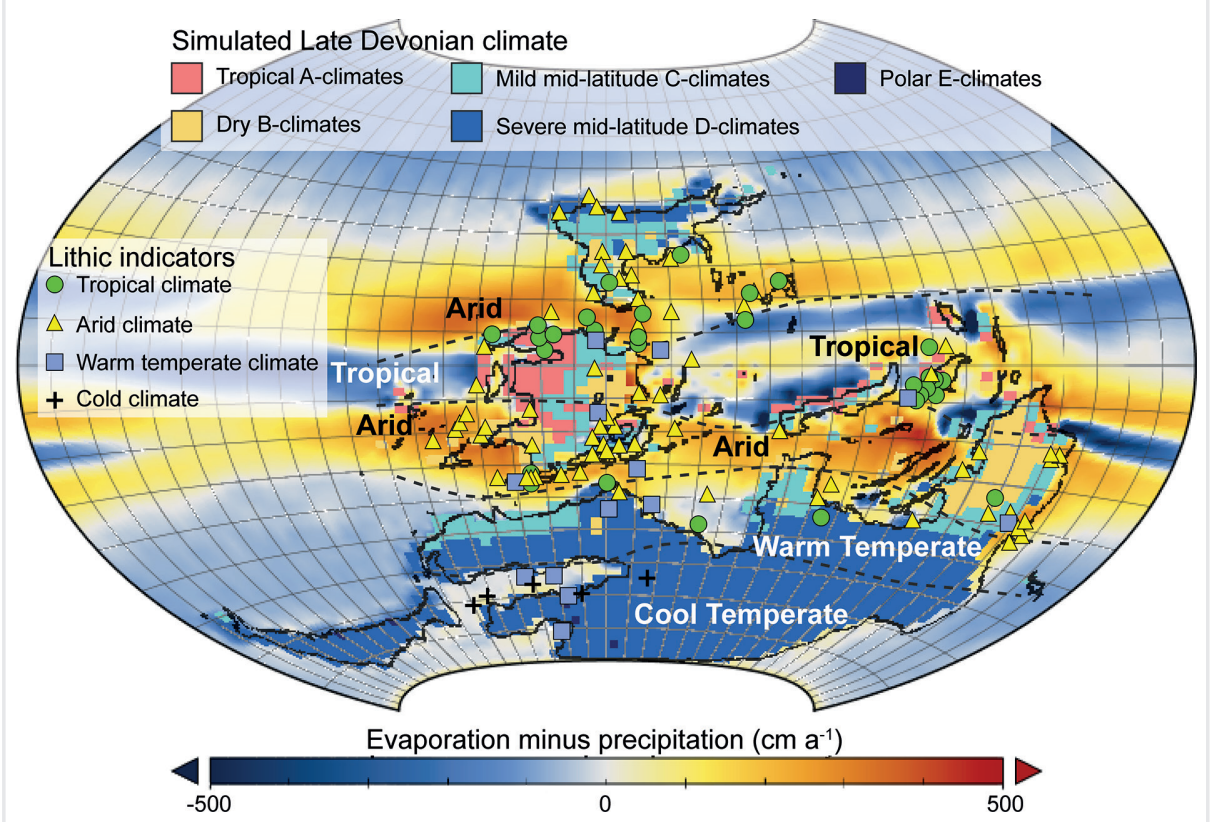

The breadth of presentations delivered during the meeting reflected many aspects of this strategy: some focused on well-identified climate phenomena such as the Walker Pacific circulation during the Last Glacial Maximum occurring in the different models; others featured technical advances within a single model (e.g. modeling of oxygen and carbon isotopes), or introduced sophisticated statistical techniques of meta-modeling to simplify and summarize process-based model outputs. An entire session was also devoted to transient experiments.

The range of scientific challenges to be addressed within PMIP keeps expanding; there are now 13 PMIP working groups. Some are defined along time periods, others along crosscutting themes, such as "variability" or "Past2Future". This structure will be maintained, keeping in mind that working groups are efficient and flexible structures that may merge or evolve as the community recognizes significant progress or feels the need to re-focus its research priorities.

\section{ACKNOWLEDGEMENTS}

The meeting was supported by PAGES, the WCRP, the Universities of Louvain, of Gent and of Namur, the Province de Namur, the Belgian National Fund for Scientific Research, the European Research Council, the Leverhulme Trust, HP and Intel. The program and abstracts are available at http://www.climate.be/pmip3, and info on PMIP at http://pmip3.Isce.ipsl.fr.

\section{AFFILIATIONS}

'Georges Lemaitre Centre for Earth and Climate Research, Université catholique de Louvain, Louvain-laNeuve, Belgium

Institute for Coastal Research, Helmholz-Zentrum, Geesthacht, Germany

${ }^{3}$ Laboratoire des Sciences du Climat et de l'Environnement, Institut Pierre et Simon Laplace, Gif-surYvette, France

\section{CONTACT}

Michel Crucifix: michel.crucifix@uclouvain.be

\section{REFERENCES}

De Vleeschouwer D et al. (2014) Global Planet Change 120: 65-80

Scotese CR, Barrett SF (1990) In: McKerrow WS Scotese CR (Eds) Paleozoic Paleogeography and Biogeography, Geological Society of London, 75-85

Figure 1: Data-Model comparison for a "median orbit" Late Devonian simulation. The HadSM3 slab model simulated climate types and evaporation minus precipitation data are compared to lithic indicators of paleoclimate (PALEOMAP project; Scotese and Barrett 1990). Modified from De Vleeschouwer et al. 2014 